by the formulæ II and IV have been established by acid hydrolysis and identification of the fragments, namely, glycerol (from II), ethylene glycol (from IV) and glycollic aldehyde (from II and IV). Confirmation of these results has been obtained from experiments carried out with the benzoyl and $p$-nitrobenzoyl derivatives of the alcohols.

Proof of the structure of the alcohols represented by VI may be illustrated by reference to that obtained from $\alpha$-methyl-L-rhamnopyranoside. This particular alcohol affords upon hydrolysis glycollic aldehyde (2,4-dinitrophenylhydrazone, melting point $86^{\circ}$ ) and an optically active 1,2-propanediol (bis p-nitrobenzoate, melting point $109^{\circ},[\alpha]_{D}^{3 \cdot 3}+48 \cdot 5^{\circ}$ (acetone)), which proved to be identical with that obtained from I (dextro)-lactic acid and its methyl ester by reduction with lithium aluminium hydride.

We have also found that reduction of aldehydes, formed by periodate oxidation of glycosides, is also applicable to oligosaccharides. Thus $\beta$-methyl maltoside has given VII whereas sucrose has afforded VIII.

Furthermore, the fact that the latter, which contains only one asymmetric carbon atom $\left(\mathbf{C}_{1}\right.$ of the original D-glucose moiety), has a negative rotation shows that in sucrose the anomeric linkage at the glucose residue is of the $\alpha$-type, inasmuch as all alcohols of the type represented by II (an analogue of VIII) derived from $\alpha$-alkyl-Dglucopyranosides have a negative rotation, whereas all those derived from $\beta$-alkyl-Dglucopyranosides have a positive rotation.

Further details of this work will be published later.

$$
\begin{array}{ll}
\text { M. Abdel Ake er } & \text { F. Smith } \\
\text { J. E. Cadotte } & \text { J. W. Van Cleve } \\
\text { R. Montgomery } & \text { Bertha A. Lewis }
\end{array}
$$

Division of Agricultural Biochemistry,

University of Minnesota,

St. Paul, Minnesota. Aug. 28.

${ }^{1}$ Fleury, Herissey and Joly, J. Pharm. Chim., 20, 149 (1934). ${ }^{2}$ Hudson and Jackson, J. Amer. Chem. Soc., 58, 378 (1936) ; 59, 994

\section{A New Synthesis of 2-Deoxy-D-ribose}

IT has long been a matter of interest to synthesize 2-deoxy-D-ribose, a component sugar of deoxyribonucleic acid, and several methods have been reported ${ }^{1}$. We wish to communicate some results which we obtained recently.

$\mathrm{D}$-Arabinose was converted into ribulose by heating it in pyridine ${ }^{2}$. Ribulose isolated as its 0 -nitrophenyl hydrazone was reduced as such with Raney's nickel catalyst to the 2-deoxy-2-amino-pentitols, the crystallization of which failed. The amino-alcohols were converted into deoxy-pentose by treatment with nitrous acid. The course of the reaction may be interpreted as a sort of 'semipinacolinic deamination's. 2-Deoxy-D-ribose was isolated as its benzylphenyl hydrazone melting at $125 \cdot 5-126 \cdot 5^{\circ} \mathrm{C} .,[\alpha]_{D}^{11}$ being $-15 \cdot 25^{\circ}$. The overall yield was about 3 per cent. The whole course of the reaction is represented as follows :
We are indebted to Prof. K. Makino and Mr. K. Ohta, of the College of Medicine, Kumamoto University, for an authentic specimen of deoxyribose, and we are grateful to Prof. S. Akabori, of the College of Science, Osaka University, for his suggestions and encouragement.

\section{Y. Matsuseima}

Y. IMANAGA

Department of Chemistry,

Women's University, Nara. Oct. 25.

${ }^{1}$ Sowden, J. C., J. Amer. Chim. Soc., 71, 1897 (1949). Kent, P. W. Stacey, M., and Wiggins, L. F., J. Chem. Soc., 1232 (1949). Overend W. G., Stacey, M., and Wiggins, L. F., J.Chem. Soc., 1358 (1949). Oht Indust., Biochem. 406 (1951).

${ }^{2}$ Glatthaar, C., and Reichstein, T., Helv. Chim. Acta, 18, 80 (1935). ${ }^{3}$ Matsushima, Y., Bull. Chem. Soc. Japan, 24, 144 (1951).

\section{Transglucosylation of Aromatic N-Glucosides}

AェтночGH the transglucosylation of $\mathrm{O}$-glucosides is not very practicable and has been described hitherto only in isolated cases ${ }^{1}$, the same mechanism appears in the case of $\mathrm{N}$-glucosides of primary aromatic amines and seems to be fairly easy and to proceed according to the reaction:<smiles>O=CCC(O)C(O)C(O)C(O)CO</smiles>

The first example of this reaction was given in 1936 by R. Kuhn and A. Dansi ${ }^{2}$, who in this way prepared nitroxylidine-glucoside from $p$-toluidine-glucoside, but the yield was very low. In 1948, J. Inoue and K. Onodera described two further reactions, namely, the preparation of aniline-glucoside and $m$ - or $p$-nitraniline-glucoside from $p$-toluidine-glucoside; however, the description of the latter seems to me doubtful ("white tabular crystals (?), m.p. 120-122", of aniline N-D-glucoside" ${ }^{\prime}$ ).

Since this process appears to be of significance both from the chemical and biochemical points of view, we have made detailed investigations of the conditions and mechanism of the reaction. Our conclusions can be summarized as follows :

(1) The resction is dependent upon $p \mathrm{H}$.

(2) It is in certain circumstances reversible (see examples 4-5, 6-7 and 8-9 in the accompanying table).

(3) The reaction will proceed to completion in solvents such as methyl alcohol and ethyl alcohol in a few minutes at low temperature with very satisfactory yields; Inoue and Onodera heated the reaction mixtures for eight hours. We find that application of heat serves only to speed up the solution of the starting reactants.

(4) The reactions in absolute alcohols leave little doubt that the process is really transglucosylation rather than hydrolysis followed by redistributive reglucosylation. This conclusion is confirmed by the 